\title{
The Effects of Air Pollutants on the Prevalence of Common Ear, Nose, and Throat Diseases in South Korea: A National Population-Based Study
}

\author{
Mina Park ${ }^{1}$ (i) $\cdot$ Ji Sung Lee ${ }^{2}$ (D) $\cdot$ Moo Kyun Park ${ }^{3}$ (i) \\ ${ }^{1}$ Department of Otorhinolaryngology-Head and Neck Surgery, Seoul Medical Center, Seoul; ${ }^{2}$ Clinical Research Center, Asan Institute of Life \\ Sciences, Asan Medical Center, University of Ulsan College of Medicine, Seoul; ${ }^{3}$ Department of Otorhinolaryngology-Head and Neck Surgery, \\ Seoul National University Hospital, Seoul National University College of Medicine, Seoul, Korea
}

Objectives. The effects of air pollutants on upper airway disease development have been seldom studied. In this study, we evaluated the effects of air pollution on the prevalence of ENT diseases.

Methods. We identified cases of ENT disease occurring in 2009, as recorded by the Korea National Health and Nutrition Examination Survey, and explored their associations with the levels of five air pollutants: sulfur dioxide $\left(\mathrm{SO}_{2}\right)$, nitrogen dioxide $\left(\mathrm{NO}_{2}\right)$, ozone $\left(\mathrm{O}_{3}\right)$, carbon monoxide $(\mathrm{CO})$, and particulate matter $\left(\mathrm{PM}_{10}\right.$ particles; particulates $\leq 10 \mu \mathrm{m}$ in aerodynamic diameter). Subjects diagnosed with at least one of the five studied ENT diseases were included in analysis, but those aged under 19 years were excluded. Linear associations between ENT disease frequency and pollutant levels were evaluated by calculating Spearman correlations. After adjusting for age, gender, and geographic region, multivariate logistic regression was used to obtain odds ratios (OR) with $95 \%$ confidence intervals (CI).

Results. A total of 7,399 subjects with ENT diseases were identified. A linear association was evident between $\mathrm{PM}_{10}$ concentration and the frequency of septal deviation (Spearman coefficient, 0.507; $P=0.045$ ). After adjustment, the $\mathrm{PM}_{10}$ level was associated with high odds ratios for chronic rhinosinusitis (1.22; 95\% CI, 1.02 to 1.46) and septal deviation (1.43; $95 \% \mathrm{CI}, 1.22$ to 1.67$)$. Both of these conditions were more prevalent in males.

Conclusion. We found that increased ambient concentrations of $\mathrm{PM}_{10}$ particles were clearly associated with increased the risk of chronic rhinosinusitis and septal deviation; the exposure-response relationship was definitive.

Keywords. Air Pollution; Health Impact Assessment; Respiratory Tract Infections; Nose

\section{INTRODUCTION}

Air pollution is a recognized risk factor for several diseases and health conditions. Several studies have shown relationships between lower respiratory tract disease frequency and air pollut-

\footnotetext{
- Received May 2, 2018

Revised December 12, 2018

Accepted December 20, 2018

- Corresponding author: Moo Kyun Park

Department of Otorhinolaryngology-Head and Neck Surgery, Seoul

National University Hospital, Seoul National University College of

Medicine, 101 Daehak-ro, Jongno-gu, Seoul 03080, Korea

Tel: +82-2-2072-3649, Fax: +82-2-745-2387

E-mail: entpmk@gmail.com
}

ant levels. In developing countries, at least $42 \%$ of all lower respiratory tract infections are attributable to air pollution [1]. Infections of the upper respiratory tract are both common and serious [2]. The upper respiratory tract is the first region of the respiratory system to come into contact with air pollutants; upper respiratory infections influence the status of the lower respiratory tract, inducing morbidity therein and creating considerable economic burdens [2]. However, the relationship between upper respiratory tract infection frequency and the levels of air pollutants remains poorly understood.

Some studies have revealed associations between air pollution levels and ENT diseases; one study found a relationship between air pollutant levels and olfactory dysfunction [3], while

Copyright (C) 2019 by Korean Society of Otorhinolaryngology-Head and Neck Surgery.

This is an open-access article distributed under the terms of the Creative Commons Attribution Non-Commercial License (http://creativecommons.org/licenses/by-nc/4.0)

which permits unrestricted non-commercial use, distribution, and reproduction in any medium, provided the original work is properly cited. 
others found a relationship with allergic rhinitis [4,5]. Although the cited works showed that air pollution influenced ENT health, systematic research has instead emphasized the effects of air pollution in general; works focusing on ENT conditions in adults are uncommon. The objective of the present study was to analyze relationships between ambient air pollutant levels and the prevalence of various ENT diseases.

\section{MATERIALS AND METHODS}

\section{Air pollution}

Every year, the Korean National Institute of Environmental Research makes regional air pollution data freely available in a variety of formats on the AirKorea website (http://www.airkorea. or.kr/eng/stationInformation?pMENU_NO=158); we used the 2009 data in the present study. The data were collected from 251 locations in 79 areas of South Korea, and are presented according to administrative region. The hourly concentrations of particulate matter $(\mathrm{PM}) \leq 10 \mu \mathrm{m}$ according to its aerodynamic diameter $\left(\mathrm{PM}_{10} ; \mu \mathrm{g} / \mathrm{m}^{3}\right)$, and nitrogen dioxide $\left(\mathrm{NO}_{2} ; \mathrm{ppm}\right)$, ozone $\left(\mathrm{O}_{3} ; \mathrm{ppm}\right)$, sulfur dioxide $\left(\mathrm{SO}_{2} ; \mathrm{ppm}\right)$, and carbon monoxide $(\mathrm{CO} ; \mathrm{ppm})$ concentrations were recorded. $\mathrm{PM}_{10}$ values were measured using a beta-ray absorption method and $\mathrm{NO}_{2}$ was measured using a chemiluminescence assay. $\mathrm{O}_{3}$ was assayed by ultraviolet photometry, $\mathrm{SO}_{2}$ by pulsed ultraviolet fluorescence, and $\mathrm{CO}$ using a nondispersive infrared method.

\section{Study sample}

The Korea National Health and Nutrition Examination Survey (KNHANES) has been conducted in South Korea since 1988 by the Korea Centers for Disease Control and Prevention to investigate prevalence and potential control of a variety of diseases. We used the 2009 data, which were the first to include information on the presence or absence of otorhinolaryngology diseases including allergic rhinitis, chronic otitis media, laryngeal disease, chronic sinusitis, and septal deviation.

Of the total of 10,065 individuals who participated in the health survey and underwent medical check-ups including ENT inspections, we excluded those who were under 19 years of age

\section{HIIGHLIIGIHITS}

- The particulate matter $\leq 10 \mu \mathrm{m}$ in aerodynamic diameter $\left(\mathrm{PM}_{10}\right)$ concentrations showed positive association with the risk of chronic rhinosinusitis in male.

- Increased levels of $\mathrm{PM}_{10}$ were related with increased risk of septal deviation in male.

- This represents the $\mathrm{PM}_{10}$ concentration is associated with chronic rhinosinusitis and septal deviation and further study is needed to figure out the causal relationship. $(n=7,527)$ and those who did not have at least one of five ENT diseases (chronic otitis media, chronic rhinosinusitis, allergic rhinitis, septal deviation, and benign laryngeal disease) $(n=128)$. Finally, a total of 7,399 individuals were analyzed. The KNHANES was conducted after approval was obtained from the Institutional Review Board of the Korea Centers for Disease Control and Prevention (approval No. 2009-01CON-03-2C).

\section{ENT evaluation}

ENT diseases were diagnosed by trained residents. Chronic otitis media was diagnosed in those with tympanic membrane perforations and/or cholesteatoma, including retraction pockets, but not in those with congenital cholesteatoma and/or otitis media with effusion, including patients into whom ventilation tubes had been inserted. Chronic rhinosinusitis was diagnosed in those with nasal polyps evident endoscopically or with at least two of the following symptoms: anterior/posterior nasal drip, nasal obstruction, facial pain/tenderness, and olfactory dysfunction more than 3 months in duration (either an anterior/posterior nasal drip or nasal obstruction was required as a presenting symptom). Allergic rhinitis was diagnosed in those with at least two of the following four symptoms: sneezing, rhinorrhea, nasal obstruction, and itching during the past year. Septal deviation was diagnosed in those in whom endoscopy revealed that the septum was asymmetrically displaced to either the left or right. The endoscopy exams were performed by experienced otorhinolaryngology residents. To enhance the objectivity of diagnosis for septal deviation, the endoscopic exam was performed after nasal mucosa constriction using an epinephrine spray. In the case of a C-shaped septal deviation, the side with the narrower nasal cavity was checked; for an S-shaped septal deviation, both sides were checked.

Benign laryngeal disease was diagnosed in those exhibiting at least one of the following findings on laryngoscopy: a vocal cord nodule/polyp/cyst, Reinke's edema, vocal cord palsy, contact granuloma, sulcus vocalis, vocal keratosis, an epiglottal cyst, laryngitis, and/or a laryngeal papilloma.

\section{Statistical analysis}

All KNHANES data were derived using a stratified, multi-stage, clustered probability sampling method to ensure that they were representative of the entire South Korean population, i.e., population weighting was applied during analysis. The SAS ver. 9.4 (SAS Institute Inc., Cary, NC, USA) PROC SURVEY procedure was used for stratification, and to create primary sampling units and construct population weights.

Air pollutant level and ENT disease prevalence data are presented as weighted mean (with $95 \%$ confidence intervals [CI]) and weighted prevalence (with $95 \% \mathrm{CI}$ ), respectively. Linear associations between air pollutant levels and ENT disease prevalence according to region were analyzed by Spearman's correlation analysis. Air pollutants affecting the prevalence of ENT dis- 
ease were subjected to multivariable logistic regression after adjusting for age, gender, and region. A two-tailed $P$-value $<0.05$ was considered to reflect significance. All analyses were performed using the SAS software.

\section{RESULTS}

\section{Prevalence of ENT diseases}

The prevalence of all studied ENT diseases is shown in Fig. 1. Of the five diseases evaluated, septal deviation was the most common in both males and females. With the exceptions of chronic rhinosinusitis and septal deviation, disease prevalence was similar between males and females; the former two diseases were much more common in males (chronic rhinosinusitis: odds ratio [OR], 7.55 vs. $4.70, P<0.001$; septal deviation: $\mathrm{OR}, 54.19$ vs. $34.88, P<0.001)$.

\section{Association between air pollutant levels and ENT disease frequency}

The concentrations of ambient air pollutants and prevalence of ENT diseases in 16 administrative regions of Korea are shown in Supplementary Table 1 . The Spearman correlation coefficients between the level of each air pollutant and each ENT disease are listed in Table 1. Only the $\mathrm{PM}_{10}$ concentration and septal de-

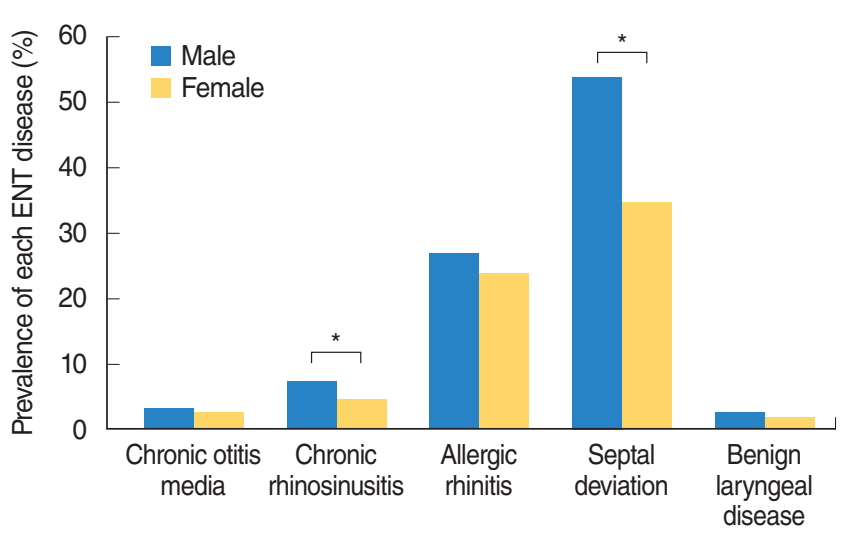

Fig. 1. Prevalence of each ENT disease by gender in Korean adults. ${ }^{*} P<0.05$. viation correlated significantly (Spearman correlation coefficient, $0.507 ; P=0.045$ ) (Fig. 2).

Adjusted ORs for the association between each disease and age, gender, and the levels of the five studied ambient air pollutants are listed in Table 2. Chronic otitis media was associated with older age (OR, 1.04; 95\% CI, 1.03 to 1.05, $P=0.000$ ); allergic rhinitis was associated with younger age (OR, 0.98; $95 \%$ CI, 0.98 to $0.99 ; P=0.000$ ). Chronic rhinosinusitis and septal deviation were more common in males, with ORs of 1.67 (95\% CI, 1.34 to $2.09 ; P=0.000)$ and $2.29(95 \% \mathrm{CI}, 2.05$ to $2.56 ; P=$ 0.000 ), respectively.

The strongest association was between septal deviation and $\mathrm{PM}_{10}$ levels. When the $\mathrm{PM}_{10}$ level increased by $1 \mu \mathrm{g} / \mathrm{m}^{3}$, septal deviation also increased significantly, with an OR of 1.43 (95\% CI, 1.22 to $1.67 ; P=0.000$ ). The next strongest association was that between chronic rhinosinusitis and the $\mathrm{PM}_{10}$ level. As the $\mathrm{PM}_{10}$ level increased by $1 \mu \mathrm{g} / \mathrm{m}^{3}$, chronic rhinosinusitis also increased significantly, with an OR of $1.22(95 \% \mathrm{CI}, 1.02$ to 1.46; $P=0.031)$. No other air pollutant was associated with an increased prevalence of an ENT disease.

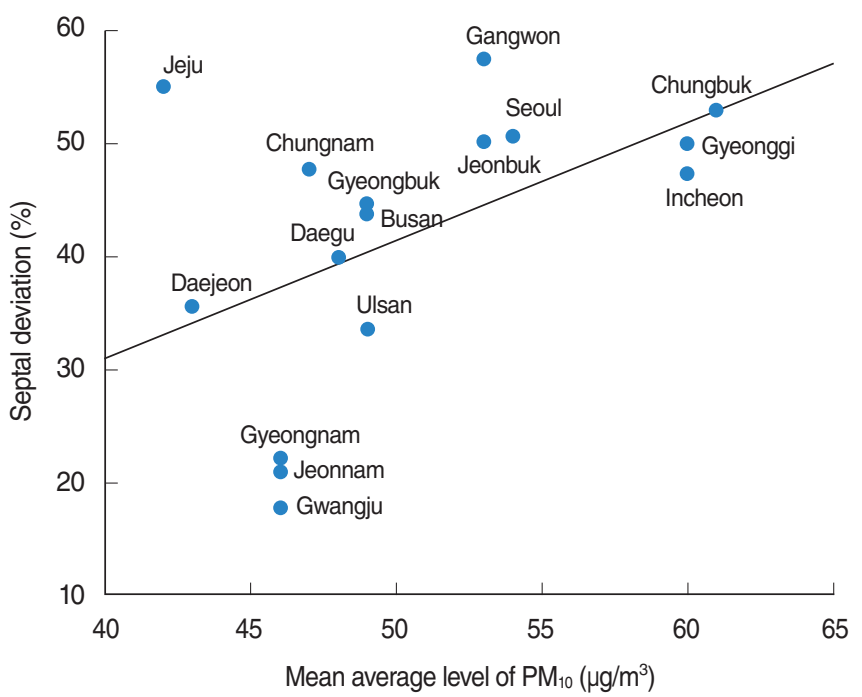

Fig. 2. Correlation between particulate matter $\leq 10 \mu \mathrm{m}$ in aerodynamic diameter $\left(\mathrm{PM}_{10}\right)$ levels and the prevalence of septal deviation in 16 administrative regions of South Korea.

Table 1. Correlation coefficients between air pollutant levels and ENT disease incidence

\begin{tabular}{|c|c|c|c|c|c|c|c|c|c|c|}
\hline \multirow{2}{*}{ Variable } & \multicolumn{2}{|c|}{ Chronic otitis media } & \multicolumn{2}{|c|}{ Chronic rhinosinusitis } & \multicolumn{2}{|c|}{ Allergic rhinitis } & \multicolumn{2}{|c|}{ Septal deviation } & \multicolumn{2}{|c|}{ Laryngeal benign disease } \\
\hline & $r$ & $P$-value & $r$ & $P$-value & $r$ & $P$-value & $r$ & $P$-value & $r$ & $P$-value \\
\hline $\mathrm{SO}_{2}$ & -0.292 & 0.273 & -0.196 & 0.467 & -0.318 & 0.230 & -0.083 & 0.759 & -0.207 & 0.442 \\
\hline $\mathrm{NO}_{2}$ & -0.444 & 0.085 & 0.111 & 0.681 & 0.154 & 0.568 & -0.160 & 0.553 & 0.189 & 0.484 \\
\hline $\mathrm{O}_{3}$ & 0.253 & 0.344 & -0.163 & 0.547 & -0.276 & 0.302 & -0.092 & 0.735 & -0.138 & 0.611 \\
\hline $\mathrm{CO}$ & -0.328 & 0.215 & -0.080 & 0.769 & 0.033 & 0.904 & 0.440 & 0.088 & 0.005 & 0.986 \\
\hline $\mathrm{PM}_{10}$ & -0.216 & 0.421 & 0.001 & 0.996 & -0.255 & 0.341 & 0.507 & 0.045 & 0.121 & 0.654 \\
\hline
\end{tabular}

$r$ indicates Spearman correlation coefficient.

$\mathrm{SO}_{2}$, sulfur dioxide; $\mathrm{NO}_{2}$, nitrogen dioxide; $\mathrm{O}_{3}$, ozone; $\mathrm{CO}$, carbon monoxide; $\mathrm{PM}_{10}$, particulate matter $\leq 10 \mu \mathrm{m}$ in aerodynamic diameter. 
Table 2. ORs for age, gender, and the levels of five air pollutants in terms of ENT disease risks, derived by multivariate logistic regression analysis

\begin{tabular}{|c|c|c|}
\hline Variable & OR $(95 \% \mathrm{Cl})$ & $P$-value \\
\hline \multicolumn{3}{|c|}{ Chronic otitis media } \\
\hline Age & $1.04(1.03-1.05)$ & 0.000 \\
\hline Male & $1.30(0.98-1.72)$ & 0.065 \\
\hline $\mathrm{SO}_{2}$ & $0.95(0.78-1.15)$ & 0.577 \\
\hline $\mathrm{NO}_{2}$ & $0.96(0.61-1.52)$ & 0.870 \\
\hline $\mathrm{O}_{3}$ & $0.99(0.39-2.54)$ & 0.987 \\
\hline $\mathrm{CO}$ & $0.93(0.66-1.31)$ & 0.690 \\
\hline $\mathrm{PM}_{10}$ & $1.05(0.86-1.29)$ & 0.648 \\
\hline \multicolumn{3}{|c|}{ Chronic rhinosinusitis } \\
\hline Age & $1.00(1.00-1.01)$ & 0.266 \\
\hline Male & $1.67(1.34-2.09)$ & 0.000 \\
\hline $\mathrm{SO}_{2}$ & $0.87(0.74-1.03)$ & 0.107 \\
\hline $\mathrm{NO}_{2}$ & $1.02(0.73-1.43)$ & 0.906 \\
\hline $\mathrm{O}_{3}$ & $0.68(0.32-1.46)$ & 0.326 \\
\hline $\mathrm{CO}$ & $0.78(0.57-1.06)$ & 0.109 \\
\hline $\mathrm{PM}_{10}$ & $1.22(1.02-1.46)$ & 0.031 \\
\hline \multicolumn{3}{|c|}{ Allergic rhinitis } \\
\hline Age & $0.98(0.98-0.99)$ & 0.000 \\
\hline Male & $1.13(1.00-1.28)$ & 0.059 \\
\hline $\mathrm{SO}_{2}$ & $0.93(0.83-1.04)$ & 0.194 \\
\hline $\mathrm{NO}_{2}$ & $1.05(0.80-1.36)$ & 0.742 \\
\hline $\mathrm{O}_{3}$ & $0.71(0.41-1.23)$ & 0.227 \\
\hline $\mathrm{CO}$ & $1.08(0.88-1.32)$ & 0.478 \\
\hline $\mathrm{PM}_{10}$ & $0.96(0.84-1.09)$ & 0.498 \\
\hline \multicolumn{3}{|c|}{ Septum deviation } \\
\hline Age & $1.00(1.00-1.01)$ & 0.408 \\
\hline Male & $2.29(2.05-2.56)$ & 0.000 \\
\hline $\mathrm{SO}_{2}$ & $0.85(0.73-0.99)$ & 0.037 \\
\hline $\mathrm{NO}_{2}$ & $0.87(0.59-1.31)$ & 0.512 \\
\hline $\mathrm{O}_{3}$ & $1.46(0.74-2.91)$ & 0.279 \\
\hline $\mathrm{CO}$ & $1.16(0.90-1.51)$ & 0.246 \\
\hline $\mathrm{PM}_{10}$ & $1.43(1.22-1.67)$ & 0.000 \\
\hline \multicolumn{3}{|c|}{ Benign laryngeal disease } \\
\hline Age & $0.99(0.98-1.00)$ & 0.118 \\
\hline Male & $1.31(0.89-1.93)$ & 0.170 \\
\hline $\mathrm{SO}_{2}$ & $0.70(0.42-1.16)$ & 0.164 \\
\hline $\mathrm{NO}_{2}$ & $1.04(0.45-2.43)$ & 0.923 \\
\hline $\mathrm{O}_{3}$ & $0.34(0.05-2.52)$ & 0.293 \\
\hline $\mathrm{CO}$ & $0.76(0.35-1.65)$ & 0.494 \\
\hline $\mathrm{PM}_{10}$ & $0.79(0.59-1.06)$ & 0.112 \\
\hline
\end{tabular}

ORs indicate per 1,000 ppm increment for $\mathrm{SO}_{2} ; 100$ ppm, $\mathrm{NO}_{2}$ and $\mathrm{O}_{3} ; 10$ ppm, CO; $1 \mu \mathrm{g} / \mathrm{m}^{3}, \mathrm{PM}_{10}$.

$\mathrm{OR}$, odds ratio; $\mathrm{Cl}$, confidence interval; $\mathrm{SO}_{2}$, sulfur dioxide; $\mathrm{NO}_{2}$, nitrogen dioxide; $\mathrm{O}_{3}$, ozone; $\mathrm{CO}$, carbon monoxide; $\mathrm{PM}_{10}$, particulate matter $\leq 10$ $\mu \mathrm{m}$ in aerodynamic diameter.

\section{DISCUSSION}

We analyzed the prevalence of five ENT diseases in South Korea in 2009 and found that an association with ambient air pollution levels. Of the five ENT diseases and five pollutants included in our analysis, the $\mathrm{PM}_{10}$ level was most strongly associated with both chronic rhinosinusitis and/or septal deviation; an increase in the $\mathrm{PM}_{10}$ level by $1 \mu \mathrm{g} / \mathrm{m}^{3}$ was associated with a $1.22 \%$ and a $1.43 \%$ increased risk of chronic rhinosinusitis and septal deviation, respectively.

One study conducted in Beijing found that the levels of $\mathrm{PM}_{10}$, $\mathrm{NO}_{2}$, and $\mathrm{SO}_{2}$ were positively associated with the number of outpatient visits to otolaryngology departments during winter [6]. Although the study settings are different, and although we found no associations between $\mathrm{NO}_{2}$ and $\mathrm{SO}_{2}$ levels and disease, it is notable that $\mathrm{PM}_{10}$ levels were closely associated with ENT disease in two Asian studies.

PM is an air-suspended mixture of microscopic solid or liquid matter [7] and is subdivided into coarse PM (particles 2.5-10 $\mu \mathrm{m}$ in diameter), fine PM (particles 0.1-2.5 $\mu \mathrm{m}$ in diameter), and ultrafine PM (particles $0.1 \mu \mathrm{m}$ in diameter). Of these, $\mathrm{PM}_{10}$ particles are derived from road dust, material sloughed off vehicle brakes and tires, and construction activities such as crushing. Awareness of the significance of PM has grown recently; a good deal of evidence shows that PM exerts potentially damaging effects. One study found that the $\mathrm{PM}_{10}$ concentration was significantly associated with the number of emergency department visits by asthmatic patients [8]. Other research showed that $\mathrm{PM}_{2.5}$ levels were clearly associated with the prevalence of outof-hospital cardiac arrest [9]. Another study showed that total suspended particle levels influenced the prevalence of ischemic stroke [10]. The International Agency for Research on Cancer and the World Health Organization consider PM to be more hazardous than any other pollutant: PM has been designated a group 1 carcinogen [11].

Although the means by which $\mathrm{PM}_{10}$ particles induce chronic rhinosinusitis remains poorly understood, disruption of the sinonasal epithelial barrier may contribute to the development of the condition. Changes in tight junction protein levels were first recorded in subjects with nasal polyposis [12]. In the cited study, the expression levels of tight junction proteins decreased 72 hours after the nasal polyp epithelium was exposed to cytokines. A recent study found that PM particles disrupted the epithelial barrier by stimulating endocytosis and destroying cell junctions via oxidative stress and activation of a MyD88-dependent mechanism. Moreover, PM promoted the secretion of inflammatory cytokines, including interleukin-25 and interleukin-33, by the sinonasal epithelium [13].

Concerning allergic rhinitis, many previous studies have shown an association between this condition and air pollutant levels in children [14-16]. However, we found no such relationship; this may be because we excluded those under 19 years of age. The prevalence of allergic rhinitis falls with age, peaking at 37 per 1,000 subjects aged $10-15$ years, and falling to 3 per 1,000 in those aged over 65 years [17].

Although septal deviation is a common diagnosis in otolaryngology clinics, there is no consensus for the objective diagnosis of septal deviation. For this reason, the data relating to septal deviation are without strong evidence. To overcome this prob- 
lem, many previous studies have investigated the accuracy of various diagnostic modalities such as acoustic rhinometry [18], rhinomanometry [19] and nasal spectral sound analysis [20], computed tomography, and endoscopy [21]. In 2012, Sedaghat et al. [22] showed that clinical assessment including anterior rhinoscopy and nasal endoscopy before and after topical decongestion is highly accurate in forecasting which individuals would require septoplasty. In 2016, Andrades et al. [21] studied the diagnostic accuracy of various diagnostic tools in predicting nasal septum abnormalities. For localized septal deviation, computed tomography had the highest accuracy; for C-shaped and Sshaped septal deviation, nasal endoscopy showed the highest rates of achievement for sensitivity, specificity, positive prediction value, and negative prediction value. Computed tomography is independent of the operator. However, individuals are exposed to radiation, and there are high costs associated with this procedure. Meanwhile, endoscopy is dependent on the operator, with a diverse inter-observer range. However, if it is conducted by experienced experts it has high reliability as well as a low cost [21]. Moreover, considering that computed tomography is inapplicable for public health screening programs, such as that used in this study, nasal endoscopy is thought to be the most appropriate diagnostic tool.

This study showed that there is an association between $\mathrm{PM}_{10}$ levels and septal deviation. Studies in Mexico explored the change of nasal mucosa by taking biopsies from citizens in Mexico City and showed basal cell hyperplasia and squamous metaplasia in histopathology and a stack of p50 protein in immunohistochemistry. These changes might lead to nasal mucosa hypertrophy and neovascularization [7,23-25].

Our study had certain strengths. First, we used nationwide data from a representative sample of the general Korean population. Second, we found an association between air pollutant levels and the prevalence of ENT diseases; these may be accompanied by upper airway diseases. Studies on the relationships between air pollutant levels and upper airway disease frequencies are rare.

This study showed that the concentration of $\mathrm{PM}_{10}$ is positively associated with the risk of chronic rhinosinusitis and septal deviation in male. Many studies tried to show the role of gender in air pollution epidemiology. Among them, some studies reported the stronger effects on lower airway in male than in female [2634]. Abbey et al. [26] showed the relationship of $\mathrm{PM}_{10}$ with the reduced lung function in males. For this result, the authors suggested gender differences in epidemiology derived from workrelated exposures. They supported this by the cohort study, in which males spend more time outdoors and it might induces in males with genetic temperament to respiratory illness. Despite of this study for lung function, it might to be partially applicable to upper airway disease (chronic rhinosinusitis and septal deviation). However, it remains unclear whether the gender difference is a result of sex-linked biological responses (i.e., hormone, body size) or exposure patterns (i.e., activity, coexposures). Most modification seems to be made up of combination of these two factors. Excluding these factors is challenging necessary completely for identifying the relevant pathophysiology for differential air pollution influences on health $[35,36]$.

Our study also had certain limitations. First, we integrated the individual data on air pollutant levels and upper airway disease and analyzed their relationship. Thus, we cannot identify the pathophysiolgies and etiologies of ENT diseases. Second, the criteria for septal deviation are subjective. Over the past few years, several criteria for septal deviation have been used. However, official criteria for septal deviation have yet to be determined. Further studies using objective criteria are needed in the future. Third, we were unable to conduct a multi-year study. Because ENT diseases have a chronic and complex pathophysiology, investigation into chronic exposure to pollutants over several years must be performed. Further studies in the future including multi-year data are needed. Fourth, we had no data on meteorological variables, including temperature, humidity, pressure, or wind speed. Finally, we could not perform time series analysis because the KNHANES has been conducted at various times throughout the year. In conclusion, of the five air pollutants and five ENT diseases included in our present analysis, the effects of $\mathrm{PM}_{10}$ levels on both chronic rhinosinusitis and septal deviation were significant in male.

\section{CONFLICT OF INTEREST}

No potential conflict of interest relevant to this article was reported.

\section{ACKNOWLEDGMENTS}

This subject was supported by Korea Ministry of Environment (MOE) as "The Environmental Health Action Program"(2016001360009), Sejong, Republic of Korea.

\section{ORCID}

Mina Park https://orcid.org/0000-0001-5110-5134

Ji Sung Lee https://orcid.org/0000-0001-8194-3462

Moo Kyun Park https://orcid.org/0000-0002-3621-4524

\section{AUTHOR CONTRIBUTIONS}

Conceptualization: MP, MKP. Data curation: MP. Formal analysis: JSL. Funding acquisition: MKP. Methodology: MP, MKP. Project administration: MKP. Visualization: \& Writing - original draft: MP.Writing - review \& editing: MKP. 


\section{SUPPLEMENTARY MATERIAL}

Supplementary material can be found via https://doi.org/10. 21053/ceo.2018.00612.

\section{REFERENCES}

1. World Health Organization. Analysis of estimates of the environmental attributable fraction, by disease [Internet]. Geneva, $\mathrm{CH}$ : WHO Press; c2017 [cited 2018 Dec 20]. Available from: http://www.who. int/quantifying_ehimpacts/publications/preventingdisease5.pdf?ua=1.

2. West JV.Acute upper airway infections: childhood respiratory infections. Br Med Bull. 2002;61(1):215-30.

3. Calderon-Garciduenas L, Franco-Lira M, Henriquez-Roldan C, Osnaya N, Gonzalez-Maciel A, Reynoso-Robles R, et al. Urban air pollution: influences on olfactory function and pathology in exposed children and young adults. Exp Toxicol Pathol. 2010 Jan;62(1):91-102.

4. Zhang F, Krafft T, Ye B, Zhang F, Zhang J, Luo H, et al.The lag effects and seasonal differences of air pollutants on allergic rhinitis in Beijing. SciTotal Environ. 2013 Jan;442:172-6.

5. Zhang F, Wang W, Lv J, KrafftT, Xu J. Time-series studies on air pollution and daily outpatient visits for allergic rhinitis in Beijing, China. SciTotal Environ. 2011 Jun;409(13):2486-92.

6. Zhang F, Xu J, Zhang Z, Meng H, Wang L, Lu J, et al. Ambient air quality and the effects of air pollutants on otolaryngology in Beijing. Environ Monit Assess. 2015 Aug;187(8):495.

7. Calderon-Garciduenas L, Rodriguez-Alcaraz A, Garcia R, Barragan G, Villarreal-Calderon A, Madden MC. Cell proliferation in nasal respiratory epithelium of people exposed to urban pollution. Carcinogenesis. 1999 Mar;20(3):383-9.

8. Noh J, Sohn J, Cho J, Cho SK, Choi YJ, Kim C, et al. Short-term effects of ambient air pollution on emergency department visits for asthma: an assessment of effect modification by prior allergic disease history. J Prev Med Public Health. 2016 Sep;49(5):329-41.

9. Kang SH, Heo J, Oh IY, Kim J, Lim WH, Cho Y, et al. Ambient air pollution and out-of-hospital cardiac arrest. Int J Cardiol. 2016 Jan; 203:1086-92.

10. Hong YC, Lee JT, Kim H, Kwon HJ. Air pollution: a new risk factor in ischemic stroke mortality. Stroke. 2002 Sep;33(9):2165-9.

11. Hamra GB, Guha N, Cohen A, Laden F, Raaschou-Nielsen O, Samet JM, et al. Outdoor particulate matter exposure and lung cancer: a systematic review and meta-analysis. Environ Health Perspect. 2014 Sep;122(9):906-11.

12. Rogers GA, Den Beste K, Parkos CA, Nusrat A, Delgaudio JM, Wise SK. Epithelial tight junction alterations in nasal polyposis. Int Forum Allergy Rhinol. 2011 Jan-Feb;1(1):50-4.

13. London NR Jr, Tharakan A, Ramanathan M Jr. The role of innate immunity and aeroallergens in chronic rhinosinusitis. Adv Otorhinolaryngol. 2016;79:69-77.

14. Nicolussi FH, Santos AP, Andre SC, Veiga TB, Takayanagui AM. Air pollution and respiratory allergic diseases in schoolchildren. Rev Saude Publica. 2014 Apr;48(2):326-30.

15. Brauer M, Hoek G, Van Vliet P, Meliefste K, Fischer PH, Wijga A, et al. Air pollution from traffic and the development of respiratory infections and asthmatic and allergic symptoms in children. Am J Respir Crit Care Med. 2002 Oct;166(8):1092-8.

16. Brauer M, Hoek G, Smit HA, de Jongste JC, Gerritsen J, Postma DS, et al. Air pollution and development of asthma, allergy and infections in a birth cohort. Eur Respir J. 2007 May;29(5):879-88.

17. Pedersen PA, Weeke ER. Allergic rhinitis in Danish general practice: prevalence and consultation rates. Allergy. 1981 Aug;36(6):375-9.
18. Mamikoglu B, Houser S, Akbar I, Ng B, Corey JP.Acoustic rhinometry and computed tomography scans for the diagnosis of nasal septal deviation, with clinical correlation. Otolaryngol Head Neck Surg. 2000 Jul;123(1 Pt 1):61-8.

19. Szucs E, Clement PA. Acoustic rhinometry and rhinomanometry in the evaluation of nasal patency of patients with nasal septal deviation. Am J Rhinol. 1998 Sep-Oct;12(5):345-52.

20. Choi H, Park IH, Yoon HG, Lee HM. Diagnostic accuracy evaluation of nasal sound spectral analysis compared with peak nasal inspiratory flow in nasal septal deviation. Am J Rhinol Allergy. 2011 MarApr;25(2):e86-9.

21. Andrades P, Cuevas P, Danilla S, Bernales J, Longton C, Borel C, et al. The accuracy of different methods for diagnosing septal deviation in patients undergoing septorhinoplasty: a prospective study. J Plast Reconstr Aesthet Surg. 2016 Jun;69(6):848-55.

22. Sedaghat AR, Busaba NY, Cunningham MJ, Kieff DA. Clinical assessment is an accurate predictor of which patients will need septoplasty. Laryngoscope. 2013 Jan;123(1):48-52.

23. Calderon-Garciduenas L, Rodriguez-Alcaraz A, Villarreal-Calderon A, Lyght O, Janszen D, Morgan KT. Nasal epithelium as a sentinel for airborne environmental pollution. Toxicol Sci. 1998 Dec;46(2): 352-64.

24. Calderon-Garciduenas L, Rodriguez-Alcaraz A, Valencia-Salazar G, Mora-Tascareno A, Garcia R, Osnaya N, et al. Nasal biopsies of children exposed to air pollutants. Toxicol Pathol. 2001 Sep-Oct;29(5): 558-64.

25. Calderon-Garciduenas L, Valencia-Salazar G, Rodriguez-Alcaraz A, Gambling TM, Garcia R, Osnaya N, et al. Ultrastructural nasal pathology in children chronically and sequentially exposed to air pollutants. Am J Respir Cell Mol Biol. 2001 Feb;24(2):132-8.

26. Abbey DE, Burchette RJ, Knutsen SF, McDonnellWF, Lebowitz MD, Enright PL. Long-term particulate and other air pollutants and lung function in nonsmokers. Am J Respir Crit Care Med. 1998 Jul;158(1): 289-98.

27. Galizia A, Kinney PL. Long-term residence in areas of high ozone: associations with respiratory health in a nationwide sample of nonsmoking young adults [dsee comments]. Environ Health Perspect. 1999 Aug;107(8):675-9.

28. Korrick SA, Neas LM, Dockery DW, Gold DR, Allen GA, Hill LB, et al. Effects of ozone and other pollutants on the pulmonary function of adult hikers. Environ Health Perspect. 1998 Feb;106(2):93-9.

29. Wang B, Peng Z, Zhang X, Xu Y,Wang H, Allen G, et al. Particulate matter, sulfur dioxide, and pulmonary function in never-smoking adults in Chongqing, China. Int J Occup Environ Health. 1999 JanMar;5(1):14-9.

30. Ackermann-Liebrich U, Leuenberger P, Schwartz J, Schindler C, Monn C, Bolognini G, et al. Lung function and long term exposure to air pollutants in Switzerland. Study on Air Pollution and Lung Diseases in Adults (SAPALDIA) Team. Am J Respir Crit Care Med. 1997 Jan;155(1):122-9.

31. Chestnut LG, Schwartz J, Savitz DA, Burchfiel CM. Pulmonary function and ambient particulate matter: epidemiological evidence from NHANES I. Arch Environ Health. 1991 May-Jun;46(3):13544.

32. Jedrychowski W, Krzyzanowski M. Ventilatory lung function and chronic chest symptoms among the inhabitants of urban areas with various levels of acid aerosols: prospective study in Cracow. Environ Health Perspect. 1989 Feb;79:101-7.

33. Oosterlee A, Drijver M, Lebret E, Brunekreef B. Chronic respiratory symptoms in children and adults living along streets with high traffic density. Occup Environ Med. 1996 Apr;53(4):241-7.

34. Zeka A, Zanobetti A, Schwartz J. Individual-level modifiers of the effects of particulate matter on daily mortality. Am J Epidemiol. 2006 May;163(9):849-59. 
35. Clougherty JE. A growing role for gender analysis in air pollution epidemiology. Environ Health Perspect. 2010 Feb;118(2):167-76.
36. Clougherty JE. A growing role for gender analysis in air pollution epidemiology. Cien Saude Colet. 2011Apr;16(4):2221-38. 